\title{
Truck Driver Fatally Injured When the Forklift He Was Operating Falls off a Loading Dock - Massachusetts
}

Release Date: February 29, 2016

Investigation: \# 13-MA-036-01
Massachusetts Department of Public Health Occupational Health Surveillance Program

\section{SUMMARY}

On December 20, 2013, a 51-year-old male truck driver (victim) was fatally injured while operating a stand-up forklift on an elevated loading dock at a produce center. The forklift fell off the loading dock causing the victim to fall out of the forklift operator's area and the forklift then landed partially on top of him. A co-worker immediately placed a call for emergency medical services (EMS). Then about 20 people, some who were co-workers, lifted the forklift off of the victim. The local police and EMS arrived at the incident location within minutes. The victim was transported to a local hospital where he was pronounced dead five days later.

Contributing factors identified in this investigation included operating forklifts on loading docks with no protective edge barriers and the lack of a forklift operator restraint system.

The Massachusetts FACE Program concluded that to prevent similar occurrences in the future, employers should:

- Prohibit forklifts from loading dock locations that are not equipped with protective edge barriers; and

- Consider installing protective barriers at the loading dock edge to minimize the possibility of employees and equipment falling off the loading dock.

In addition, forklift manufacturers should:

- Adopt and implement the concept of Prevention through Design (PtD) and redesign the stand-up counterbalanced forklift operator area to include restraint systems.

\section{INTRODUCTION}

On January 6, 2014, the Massachusetts FACE Program was alerted by the local media that on December 20, 2013, a worker was injured while operating a forklift and had died five days later. An investigation was initiated. On June 4, 2014, the Massachusetts FACE Program Director traveled to the company's office location and met with a company representative to discuss the incident. The police report, death certificate, company information, and the OSHA fatality and catastrophe report were reviewed during the course of the investigation. Photographs were taken of the incident location. 


\section{EMPLOYER}

The employer was a family-owned produce distributor that had been in business about 90 years. The company distributed a wide variety of fresh fruits and vegetables to wholesalers, retailers and other food service customers. The company owned many trucks to deliver orders placed by clients. They employed about 25 workers and 10 of these employees, including the victim, were truck drivers / warehouse workers. Most of the other employees were office workers consisting of professional staff and management. All of the truck drivers / warehouse workers used both forklifts and pallet jacks to load their trucks for delivery.

The typical work hours for the company were midnight to 2:00 p.m. The typical work week was five days per week, and sometimes a few hours on Saturday morning. On the day of the incident, the victim was working a normal shift. He arrived at the company location at 2:00 a.m. and was scheduled to work until 10:00a.m. The truck drivers / warehouse workers, including the victim, had union representation.

\section{WRITTEN SAFETY PROGRAMS AND TRAINING}

The company had an Injury and Illness Prevention Program (I2P2) and provided employees health and safety training. The content of both the I2P2 and the training provided by the employer included, but was not limited to, forklifts (powered industrial trucks) and safe driving. The company reported that they certified employees to operate forklifts and then recertified them every three years. The victim was recertified the month before the incident to operate a powered industrial truck and the recertification included a combination of classroom and hands on training. The company had an active health and safety committee that met about every six weeks. The company had workers' compensation insurance as required by law in Massachusetts (G.L. c. 152, Sec. 25A).

\section{VICTIM}

The victim was a 51-year-old male truck driver who had been employed with the company for 17 years at the time of the incident. The entire length of time the victim worked at the company he was employed as a truck driver / warehouse worker and was a member of a local Teamsters Union. His main tasks were to load trucks and make deliveries. The day of the incident, a Friday, the victim arrived to work at 2:00 a.m. and was scheduled to work a full shift. The incident occurred around 7:10 a.m., approximately 5 hours into his shift.

\section{INCIDENT LOCATION}

The facility where the incident occurred was a large produce distribution center that was made up of four rectangular shaped buildings in two rows. The buildings contained warehouse, open loading dock, office and retail space for multiple companies. Each building had loading docks located at the front and the rear of the building, totaling over 100 bays across the four buildings. The open loading docks were about 15 feet wide, and were covered with canopy roofs. Three of the four sides of the loading docks were unprotected from environmental conditions. The fourth side of the loading dock was a wall of the building (Figure 1). The company used loading dock plates when trucks were being loaded and unloaded. The produce center was open 24-hours a day, 7 days a week and was periodically a busy location with many trucks coming and going. 


\section{EQUIPMENT}

The vehicle involved in the incident was an electric, three-wheel, stand-up, counterbalanced forklift (Figure 2). The forklift was manufactured in 2013 and was being leased by the company. The overall dimensions of the forklift were approximately 3.5 feet wide by 7.3 feet high to the top of the overhead guard by 8.3 feet long, including the length of the 3 -foot long forks. The maximum lift height to the bottom of the forks was about 13 feet and it had a load capacity of 3,000 pounds. The forklift weighed approximately 6,400 pounds. The operator's area was designed so the operator would be standing and facing towards the left side of the forklift. The operator's position would allow the operator to look in the direction of travel while operating the forklift with a load on the tines. The operator's area had an opening at the rear of the forklift, which was how the operator's area was accessed. The operator's area was not equipped with a door or some other kind of operator restraint system for when the forklift was in use.

The forklift operator's area had two main hand controls, a multi-task handle and a steering handle, and two foot pedals, a brake pedal (left foot) and a power-on pedal (right foot). The multi-task handle controlled the travel direction and speed. When the multi-task handle was pushed away from the operator, the forklift traveled forks first and when the handle was pulled towards the operator, the forklift traveled with the forks behind the forklift (power unit first). The multi-task handle also controlled all of the fork movements. The steering handle rotated 360 degrees and controlled which direction the forklift turned. The manufacturer's operator's manual for the forklift contained multiple warnings. One warning listed in the operator's manual was to stay away from the edge of docks and ramps.

\section{INVESTIGATION}

At the time of the incident, the victim was outdoors on the open loading dock and had just split a double pallet. In this case, the double pallet was a full pallet and two half pallets that were strapped together. It was suggested that someone and/or a machine was trying to get by the victim and that the victim moved the forklift, power unit first, back towards the loading dock edge to move out of the way. This would have brought the forklift operator's area and the entrance opening close to the loading dock edge. It is unclear what exactly happened next, but it appears that once the person/machine went by, the victim might have attempted to move the forklift away from the loading dock edge, but the forklift traveled power unit first again and fell off the loading dock.

As the forklift fell off the loading dock, the victim fell out of the operator's area through the operator area opening and the forklift landed on top of him. A co-worker immediately placed a call for emergency medical services (EMS). Then approximately 20 people, including co-workers and people in the vicinity, worked together to lift the forklift off the victim. The local police and EMS arrived at the incident location within minutes and the victim was transported to a local hospital where he was pronounced dead five days later.

Since the incident, the employer has prohibited forklifts from the outside loading dock locations and only pallet trucks are allowed to load and unload trucks. 


\section{CONTRIBUTING FACTORS}

Occupational injuries and fatalities are often the result of one or more contributing factors or key events in a larger sequence of events that ultimately result in the injury or fatality. The Massachusetts FACE team identified the following contributing factors in this incident:

- forklifts being operated on loading docks with no edge barrier;

- lack of a forklift operator restraint system.

\section{CAUSE OF DEATH}

The medical examiner listed the cause of death as complications of blunt trauma of torso and extremities.

\section{RECOMMENDATIONS/DISCUSSION}

\section{Recommendation \#1: Employers should prohibit forklifts from loading dock locations that are not equipped with protective edge barriers.}

Discussion: In this case, the outdoor loading docks were about 15 feet deep and ran the length of the buildings. The depth of the loading dock made it difficult to keep forklifts a safe distance from the loading dock edge. ${ }^{1,2}$ The loading docks did not have designated or marked locations for trucks to back up to and unload and they were not equipped with barriers at the loading dock edges. It was reported by the employer that these loading docks can become rather congested with multiple trucks, workers on foot, and forklifts and pallet jacks being operated. A congested loading dock combined with unprotected edges greatly increases the hazard of a worker on foot or a machine falling off the loading dock. ${ }^{3}$

The best way to prevent an injury is to eliminate the hazard. Ideally in this type of situation, employers would install barriers that would prevent forklifts from falling off loading docks (see Recommendation \#2). In the meantime, employers should develop policies that prohibit forklifts from all loading docks with unprotected edges, as this company has implemented. Once a policy is developed and implemented, the employer has the responsibility of ensuring employees are adhering to the policy and enforcing the policy when necessary.

As described above, the incident occurred in a location that was made up of four buildings all with similar style loading dock space and multiple companies operating at these building. The other companies renting space at this produce distribution center should follow the lead of this employer and prohibit the use of forklifts from the loading dock area when they are not equipped with barriers at the loading dock edge.

\section{Recommendation \#2: Employers should consider installing barriers at the loading dock edge to minimize the possibility of employees and equipment from falling off the loading dock.}

Discussion: When undertaking a project, such as installing warning lines or barriers that will have to sustain a certain amount of weight and impact, the best way to do this is to hire a professional to design and install the system. The goal of a loading dock edge barrier would be that when the loading dock 
was not in use that a physical barrier is present across the loading dock edge, minimizing the fall hazards to workers or equipment. ${ }^{4}$

There are a wide variety of products available to provide protective edge barriers for loading docks, including dock guard posts with a protective heavy duty fabric barrier. The protective fabric barrier is bright in color and designed to withstand, depending on the barrier, up to 30,000 pounds. The fabric barrier is anchored by two posts and can be manually retracted into one of the posts when access is needed to the loading dock section.

In this case, one possible option would be to first create designated locations for trucks to back up to the loading docks. On each of these designated locations a post would be installed with a fabric barrier to span across the posts. Guardrails can be installed at the locations of the loading dock that are not designated as loading areas (Figure 3). Any loading dock safety improvements performed at the incident location should also be implemented throughout the entire produce distribution center where appropriate.

\section{Recommendation \#3: Manufacturers of forklifts should adopt and implement the concept of Prevention through Design (PtD) and redesign the operator area of stand- up counterbalanced forklifts to include restraint systems.}

Discussion: The concept of Prevention through Design (PtD), as it would relate to machine manufacturers, is addressing safety and health needs during the design process to prevent or minimize hazards that could result in injuries, illnesses and fatalities to machine operators and others. ${ }^{5}$ Applying PtD during the design phase of a machine would initiate the process of thinking about how the machine functions in relation to individuals who would operate, maintain, come in contact or interact with the machine in order to identify potential hazards. Once hazards are identified, the machine design can be altered to eliminate or control these hazards. The operators' areas of stand-up counterbalanced forklifts pose several well-known design-related hazards and serves as an excellent example of the potential for eliminating or minimizing injury risks through PtD.

In this case, a stand-up counterbalanced forklift was being operated at the time of the incident. The typical design of this type of forklift does not include a restraint system for the operator. Therefore, when stand-up forklift falls off an elevated surface, power unit first, the victim is usually ejected out of the operator's area with the forklift landing on top of the victim. In the operator's manual, the forklift manufacturer states "tip overs and fall from docks can cause serious injury or even death. Immediately exit and move away from the truck in these emergencies.” OSHA also references this hazard in their Powered Industrial Truck eTool that states "operators of stand-up forklifts with rear-entry access should step backwards off the forklift if a tip over occurs." 3 In this case, the actions these statements direct the forklift operator to take during a stand-up forklift tip over would not have prevented the victim's injuries.

Another injury associated with the design of stand-up forklifts has been lower limb/foot crushing. These lower limb injuries are related to the operator's area not having a barrier to keep the operator's left leg and foot safely within the operator's area while the forklift is in use. The stand-up forklift is also associated with the "under-ride" hazard, where horizontal objects can intrude into the operator's area. This hazard is typically associated with forklifts where the overhead guard is equipped with only two support posts located by the forklift's mast. This two post design leaves the power unit end of the 
canopy, the section of the operator's area where the operator enters and exits the operator's area, vulnerable to intrusion by a horizontal object such as a warehouse shelf.

It appears that most new stand-up counterbalanced forklifts are being designed and manufactured with at least three overhead guard support posts in an attempt to prevent the under-ride hazard. The forklift involved in this incident was manufactured with three supports for the overhead guard, but the design still leaves one corner of the operator's area potentially vulnerable to intrusion. If the overhead guard was designed with four posts or a support structure protecting the operating area, then the intrusion hazard would be eliminated.

If PtD had been applied to this stand-up counterbalanced forklift, the potential for the worker and machine interaction that led to the incident could have been identified and highlighted the need to redesign and/or incorporate additional engineering controls for the forklift operator's area.

\section{REFERENCES}

1. Occupational Safety and Health Administration, Code of Federal Regulations, 29 CFR 1910.178 Powered industrial trucks. Washington DC: U.S. Printing Office, Office of the Federal Register.

2. Occupational Safety and Health Administration, Pocket Guide, Worker Safety Series: Warehousing. www.osha.gov/Publications/warehousing.html

3. Occupational Safety and Health Administration, Powered Industrial Trucks (Forklift) eTool. www.osha.gov/SLTC/etools/pit/index.html

4. Nova Technology International. Dock Planning Standards. 2013. www.novalocks.com

5. National Institute for Occupational Safety and Health, Workplace Safety \& Health Topics, Prevention through Design. www.cdc.gov/niosh/topics/ptd 
Figure 1 - Loading dock where incident occurred

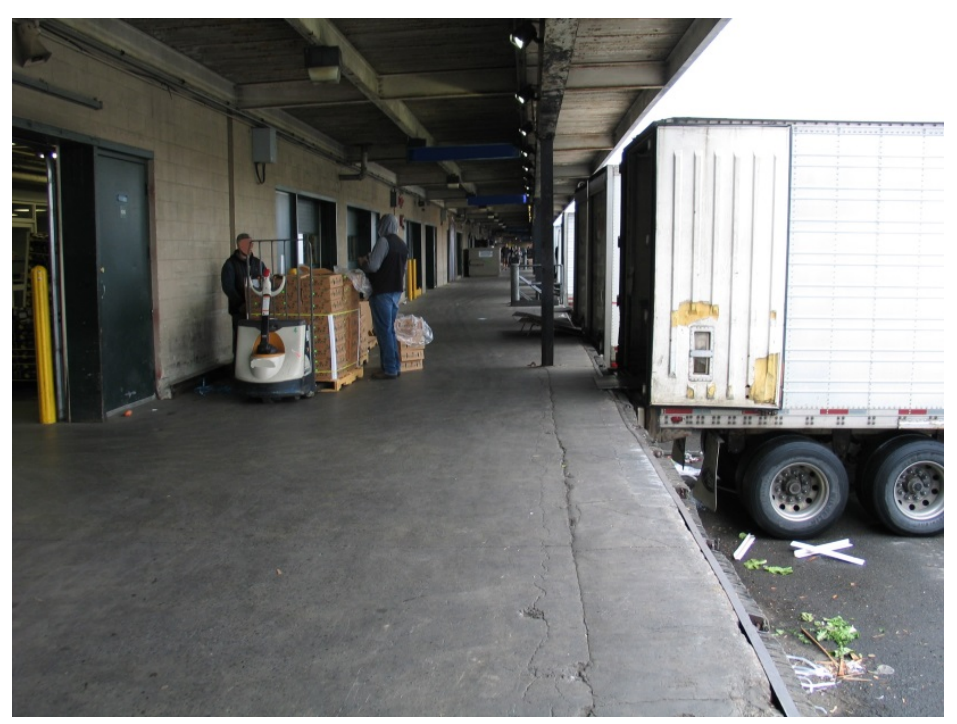

Figure 2 - Similar stand-up counterbalanced forklift

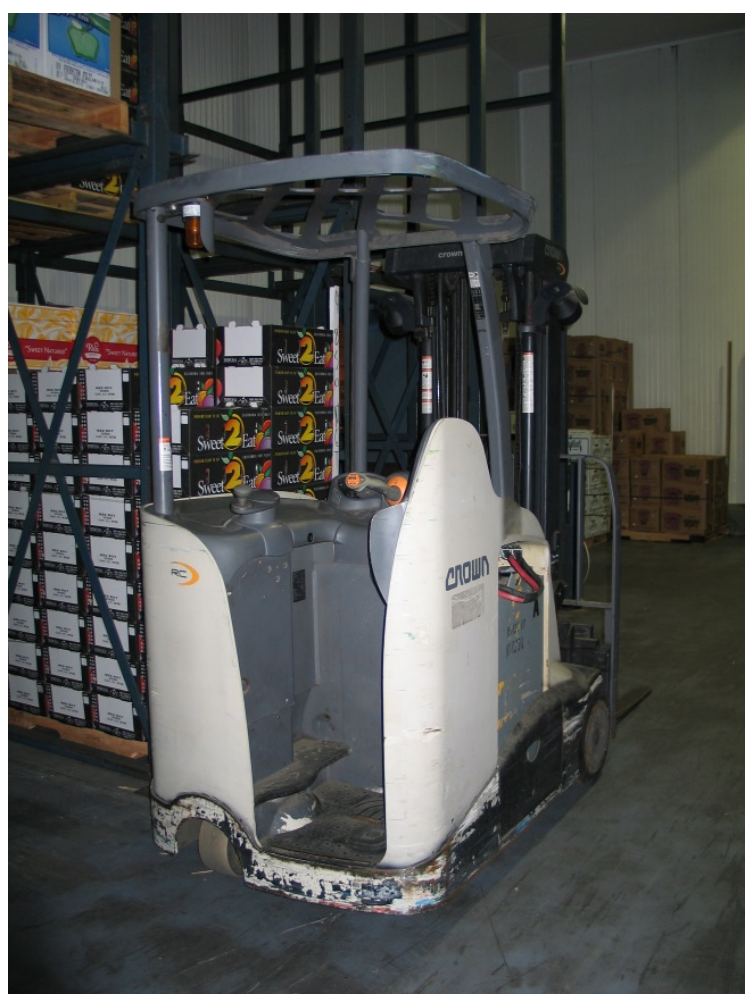


Figure 3 - Example of a protective fabric barrier

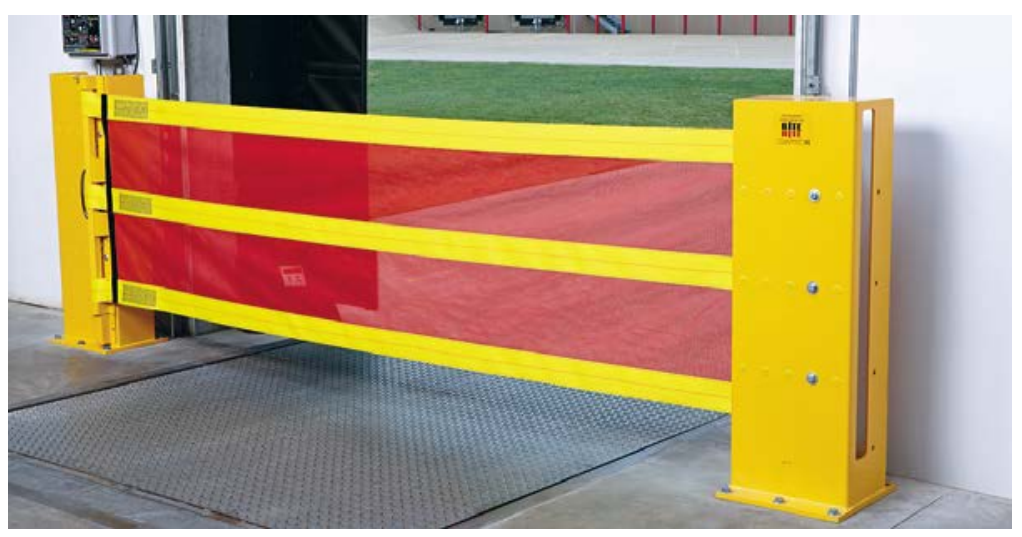


Michael A. Fiore, MS, Director

Massachusetts FACE Program

Occupational Health Surveillance Program

Massachusetts Department of Public Health
Letitia Davis, Sc.D., Ed.M., Director

Occupational Health Surveillance Program

Massachusetts Department of Public Health

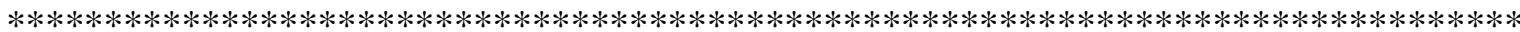

\section{FATALITY ASSESSMENT AND CONTROL EVALUATION PROGRAM}

The Massachusetts Department of Public Health, in cooperation with the National Institute for Occupational Safety and Health (NIOSH), conducts investigations on the causes of work-related fatalities. The goal of this program, known as Massachusetts Fatality Assessment and Control Evaluation (Massachusetts FACE) is to prevent future fatal workplace injuries. Massachusetts FACE aims to achieve this goal by identifying and studying the risk factors that contribute to workplace fatalities, by recommending intervention strategies, and by disseminating prevention information to employers and employees.

Massachusetts FACE also collaborates with engineering and work environment faculty at the University of Massachusetts at Lowell to identify technological solutions to the hazards associated with workplace fatalities.

NIOSH funded state-based FACE Programs currently include: California, Kentucky, Massachusetts, Michigan, New York, Oregon, and Washington.

Additional information regarding this report is available from:

Occupational Health Surveillance Program

Massachusetts Department of Public Health

250 Washington Street, 4th floor

Boston, Massachusetts 02108-4619

(617) 624-5627

\section{Evaluate this report}

We would appreciate your feedback on these reports so we may continue to improve the MA FACE project and our investigation reports. A feedback form can be found at:

www.mass.gov/eohhs/docs/dph/occupational-health/report-evaluation.doc

The completed form may be returned by fax to (617) 624-5676, by mail to FACE, 250 Washington Street, $4^{\text {th }}$ Floor, Boston, MA 02108, or by email to ma.face@state.ma.us. 